\title{
Farm-based day care services - a prospective study protocol on health benefits for people with dementia and next of kin
}

This article was published in the following Dove Press journal:

Journal of Multidisciplinary Healthcare

\author{
Siren Eriksen ${ }^{1,2}$ \\ Ingeborg Pedersen ${ }^{3}$ \\ Liv Bjerknes Taranrød' \\ Lina Harvold \\ Ellingsen-Dalskau ${ }^{3}$ \\ Bjørnar Finnanger Garshol ${ }^{3}$ \\ Tanja Louise Ibsen' \\ Øyvind Kirkevold ${ }^{1,4,5}$ \\ Elin Strandli \\ Grete Grindal Patil ${ }^{3}$ \\ 'Norwegian National Advisory Unit on \\ Aging and Health, Vestfold Hospital Trust, \\ Tønsberg, Norway; ${ }^{2}$ Faculty of Health \\ Studies, Vid Specialized University, Oslo, \\ Norway; ${ }^{3}$ Department of Public Health \\ Science, Faculty of Landscape and Society, \\ Norwegian University of Life Sciences, \\ Ås, Norway; ${ }^{4}$ Centre of Old Age \\ Psychiatry Research, Innlandet Hospital \\ Trust, Gjøvik, Norway; ${ }^{5}$ Norwegian \\ University of Science and Technology \\ (NTNU) Department of Health Sciences \\ in Gjøvik, Norway
}

Correspondence: Siren Eriksen Norwegian National Advisory Unit on Aging and Health, Vestfold Hospital Trust, Post Box 2136 3103, Tønsberg, Norway Tel +4799293231

Email siren.eriksen@aldringoghelse.no
Introduction: The increasing number of people with dementia will place a considerable challenge on the health care system and will necessitate innovation and new solutions. Day care services aim to provide meaningful activities and coping experiences for the target group. The aim of the present study is to explore the experience and potential health benefits for people with dementia attending farm-based day care services in Norway and their next of kin. Methods and design: The present study is a prospective study organized into several qualitative and quantitative sub-studies. Study period will last from 2016-2020. We use a multi-method approach and both an empirical and a constructivist view on knowledge to explore this multi-facetted phenomenon.

Discussion: Several challenges are expected, for instance, the ability to include participants with dementia and keep them within the study for the whole study period. The functioning level of participants regarding language and understanding could challenge their ability to answer. Despite having several limitations, we believe that this study with its different approaches and methods will add important knowledge to the field. Knowledge from our study could be essential for creating day care services of good quality for people with dementia and such services could reduce the burden of care for their next of kin.

Keywords: care farms, coping, farm-based activities, green care, meaningful activities, multi-method approach

\section{Background}

Dementia is a progressive condition leading to loss of function and a broad spectrum of cognitive, physical, mental and neuropsychiatric symptoms World Health Organization. ${ }^{1}$ The World Health Organization (WHO) estimates that the number of people living with dementia worldwide to be 50 million with 10 million new cases each year. ${ }^{1}$ People with mild and moderate symptoms of dementia often live in their own homes, with family members serving as their main caregivers. In the severe stage, people with dementia will be fully dependent on others and often live in long-term care facilities, such as nursing homes. As such, the WHO states that dementia is overwhelming not only for the people who have the condition but also for their caregivers and family. ${ }^{2}$ Among the estimated 80,000 Norwegians with dementia, approximately $60-65 \%$ are living in their own homes and the remaining are living in nursing homes. 3,4

Caring for people with dementia can affect caregivers in different ways. Caregiving can provide a feeling of togetherness, mastery and accomplishment 
between the person with dementia and next of kin through shared activities. ${ }^{5}$ However, being a caregiver is often associated with negative consequences described as a burden, strain or distress. The widely used concept burden of care is described as a multidimensional construct including mental, physical, social and financial consequences. ${ }^{6,7}$ Studies have shown that caring for a person with dementia may lead to poor quality of life, depression or other mental conditions, physical morbidity and increased mortality. ${ }^{2,8,9}$

The increased number of people with dementia will immensely challenge the health care system in the future. One main governmental strategy in Norway is to facilitate so that people with dementia can live in their own home as long as possible. ${ }^{10,11}$ Support from the municipality is often necessary for both people with dementia and their caregivers. Day care service is one of the services offered by municipalities aiming to provide people with dementia with meaningful activities and coping experiences and respite for their next of kin. The number of municipalities offering day care services to people with dementia living at home has increased significantly over the last 15 years, ${ }^{12}$ however, the proportion of people with dementia receiving day care services in 2014 was only $17 \%$. According to the Norwegian Dementia Plan 2020, ${ }^{10}$ the government intends to establish day care services in all Norwegian municipalities within 2020 and also calls for a greater diversity in types of services.

A national survey conducted in 2014 indicated that 40 municipalities in Norway reported to have day care services for people with dementia on farms. ${ }^{12}$ When planning our study, we conducted a survey in early 2017 and found the number of farms offering day care services in Norway to be 34 with users from 29 municipalities. ${ }^{13}$ Despite the need for complementary day care services for people with dementia, ${ }^{10}$ the number of farm-based day care services (FDC) has not increased over the last years. Further, people with dementia are one of three prioritized target groups for tailored farmbased services and social services in the Norwegian action plan for care farming. ${ }^{14}$ Lack of knowledge regarding care farming and its potential benefits for the users health is pointed out as one reason for the low number of care farm initiatives in Norwegian municipalities. ${ }^{15}$

\section{Day care services for people with dementia}

The condition of dementia is associated with a wide range of symptoms including behavioral and psychological symptoms. The role of integrated multimodal approaches in the management of these symptoms are well known. ${ }^{16,17}$ Caspar et al ${ }^{18}$ highlighted that non-pharmacological interventions for people with dementia should include consideration of physical and social environment, education/training and support for care providers, and individualized approaches that promote self-determination and continued opportunities for meaning and purpose. ${ }^{18}$

Little is known about how day care services affect health, function and quality of life for people with dementia. ${ }^{10,19}$ A systematic review by Reiner et $\mathrm{al}^{20}$ concluded that day cares designed for people with dementia might contribute to reduced incidences of behavioral problems and improve the quality of life for people with dementia. Rokstad et $\mathrm{al}^{19}$ recently reported higher quality of life for people with dementia attending day care services compared to those without services. Qualitative interviews with people with dementia attending day care reported such services positively influenced their physical functioning, cognition, wellbeing and situation at home. ${ }^{21}$ The day care service provided social stimulation, meals, and activities and maintained the daily rhythm and structure in everyday life. In addition, people with dementia experienced the day care centers as a safe place to stay and felt a sense of belonging. In a qualitative cross-national comparative study, Rokstad et $\mathrm{al}^{22}$ stated that specialist day care for people with dementia seemed to provide important support and positive outcomes for the target group and provide respite and reassurance for their caregivers.

A review by Vandepitte et $\mathrm{al}^{23}$ emphasized that day care services may decrease care burden for next of kin. An integrative review ${ }^{24}$ searched to identify the influence of day care services for people with dementia on family caregivers. The findings suggested that such services provide a feeling of safety and relief, reduce caregiver burden, and increase motivation for the role as caregiver. However, these outcomes were contingent on the perceived quality of the service, how the service met their needs for flexibility, support, information, and sharing of responsibility.

\section{FDCs for people with dementia}

Care farms could be defined as farms offering tailored and quality-based welfare services based on the available resources on the farm. ${ }^{14}$ Due to the structural changes within the agricultural sector, care farming is often seen as a part of the increased pluriactivity among Norwegian farmers, since it is commonly offered as an addition to the agricultural business. A recent review of Norwegian research on care farming for people with mental health 
problems indicates an impact on mental health as well as improved coping and social support. ${ }^{25}$ This finding is in line with international research describing services at care farms as empowerment-oriented and coping-based. Apart from contact with nature and animals, the group (as a means for social support and inclusion), type of activities (meaningful), the setting itself (homelike, small-scaled) and the service provider (farmer) have been emphasized as core qualities of care farm services. ${ }^{26-29}$

In a systematic review, Orr et $\mathrm{al}^{30}$ synthesized literature on how older people describe their sensory experiences when being in nature. These researchers observed that older people derive considerable pleasure and enjoyment in different perspectives of nature. In turn, this finding has an impact on well-being and quality of life. Hendriks et $\mathrm{al}^{31}$ also explored well-being and quality of life in people with dementia when being in nature. These researchers observed eight key themes: pleasure, relaxation, feeling fit, enjoying the beauty of nature, feeling free, the social aspect of nature, feeling useful, and memories. In a qualitative study of people with dementia attending a forest day center, Swane $^{32}$ concluded that days spent in the forest give people with dementia who live at home meaningful experiences, which they remember better than indoor activities and about which they verbally communicate more readily. When considering specific interventions, Gonzalez and Kirkevold ${ }^{33}$ reviewed and found that targeted use of gardens and garden activities may positively influence function, behavior, and well-being. Similar results are seen in animal-assisted intervention, and human-animal interaction is included in the integrative framework for care farming for people with dementia made by de Bruin et al. ${ }^{34}$

Further, de Boer et $\mathrm{al}^{35}$ investigated whether residents of care farms that provide $24 \mathrm{hr}$ nursing care participate more in physical activities and social interaction compared to residents of ordinary nursing homes. These researchers observed that care farms could be a good residential alternative to ordinary nursing homes. An attractive, homelike environment and activities that positively influence engagement and social interaction were important. ${ }^{35}$ To the best of our knowledge, the only international study focusing on FDCs for people with dementia was conducted in the Netherlands by de Bruin et al. ${ }^{34,36,37}$ They compared FDC at care farms to ordinary day care services at institutions. The study found that people with dementia had higher intake of energy and fluid and that activities were more frequent, more individually tailored and occurred more often outdoors. In addition, the activities performed at care farms required more physical effort compared to activities at institutions. ${ }^{36}$

To date, Norwegian research on this topic is limited and consists of small samples. ${ }^{38,39}$ Strandli et $\mathrm{al}^{39}$ conducted in-depth interviews with spouses living with a person with dementia attending FDC. These researchers observed that spouses experienced that day care services at farms relieved their care burden, and they reported that the services contributed to maintaining the people with dementia's own identities. They further stated that care farming could promote health in both people with dementia and next of kin. To date, we know little regarding the people with dementia attending FDC in Norway and the possible benefits and challenges for them and their next of kin.

\section{Aim and research questions}

The present study constitutes one part of a larger research project investigating FDC from different perspectives. In addition to explore people with dementia attending FDC and their next of kin as covered by the present protocol, the project investigate the farm context, and the perspectives of the farmer as a service provider and the municipality as a buyer of the FDC.

The main objective of this study is to gain knowledge about the experiences and health benefits of attending FDC among people with dementia and their next of kin. The study has five main research questions:

1. What are the characteristics of the people with dementia attending FDC and their next of kin?

2. How do health variables of people with dementia and their next of kin develop over time?

3. What characterizes people with dementia that stop attending FDC, and to what extent do these characteristics predict drop out?

4. What are the experiences of FDC for people with dementia and their next of kin?

5. How do next of kin experience the process of transition from FDC to a higher level of care for people with dementia

\section{Methods}

\section{Study setting}

FDC use the farm setting and available farming activities suitable for people with dementia. ${ }^{13}$ Examples of this could be caring for farm animals, garden activities, 
outdoor recreational activities such as walks in the area surrounding the farm, boat trips, horse and carriage rides, and picking flowers, and indoor recreational activities like leisure activities, woodwork, preparing meals, and baking. The daily structure on FDC is similar to ordinary Norwegian day care services. ${ }^{13}$ Meals and transportation of the participants to and from the venue are included like in most day services in Norway.

The health authority in the municipally is responsible for the day care center at the farm in the same way as for institutional care services. A contract between the farmer (service provider) and the health authority will be established, and the municipality covers the costs for the service. In most cases, the service provider is responsible for the activities on a day-to-day basis. However, municipal health care personnel have the formal responsibility, and the survey by Ibsen et $\mathrm{al}^{13}$ indicates that the FDCs have comparable coverage of health care personnel as ordinary day care.

\section{Design related to the specified research questions}

The present study is a prospective longitudinal study organized into several sub-studies. To study such a complex setting like FDC for people with dementia, we will use a multi-method approach. We use quantitative methods to answer research question 1, 2 and 3, and qualitative methods to answer research question 4 and 5 . We see this as a clear advantage as these approaches can provide complementary knowledge and give access to different facets of the phenomenon being explored. ${ }^{40}$ To answer the above stated research questions the following methods were chosen:

Research question 1, 2 and 3 (quantitative approach): Data will be collected over a period of 12 months with standardized instruments for both people with dementia and next of kin. Data will be collected at baseline and after 6 and 12 months. Additionally, available to the study is data from an ongoing Norwegian research study, The effects and costs of a day care center program designed for people with dementia - a 24-month controlled study (ECOD). ${ }^{19,41}$ The present study uses many of the same instruments as ECOD, which allows us to compare the possible benefits of attending FDC with ECOD groups receiving ordinary day care and no day care in a nonrandomized design.
We aim to enroll 150 dyads of people with dementia participating at FDC, and their next of kin. We will use baseline data to describe the characteristics of people with dementia and the their next of kin (research question 1), longitudinal data (baseline, 6 and 12 months) to explore the influence on health for people with dementia and care burden for next of kin over time (research question 2), and longitudinal data (baseline, 6 and 12 months) to investigate the characteristics of people with dementia who stop attending the FDC (research question 3).

Research question 4 and 5 (qualitative approach): Qualitative individual in-depth interviews will be conducted. In order to explore the influence FDC have on people with dementia and their daily lives (research question 4), 8-10 people with dementia attending FDC and 810 of their next of kin will be interviewed. In addition, observations of the participants with dementia attending FDC will also be conducted (research question 4).

For exploring the experience next of kin has when the person with dementia is transferred to other care services (research question 5), 8-10 next of kin will be interviewed.

\section{Participants and recruitment}

For the longitudinal quantitative data collection, we will recruit dyads of people with dementia and their next of kin. The focus for this study is the limited group of people attending farm-based day care services. Therefore, everyone attending the service are eligible regardless of type of dementia or dementia severity. The following eligibility criteria have been decided:

- For people with dementia: (a) attended FDC for at least 3 weeks; (b) live with next of kin or meet him/ her regularly, for a minimum average of once per week; and (c) are able to express themselves verbally and have the cognitive capacity to participate. A person with dementia will be excluded if the next of kin do not want to participate.

- For next of kin: (a) being 18 years or older; (b) live with the person with dementia or meet him/her regularly, for a minimum of once per week on average; and (c) can give written consent. Next of kin will be excluded if the person with dementia does not want to participate.

For the qualitative data collection, a purposeful sample of people with dementia and next of kin will be recruited following the same eligibility criteria. 


\section{Quantitative assessment of people with dementia and next of kin}

To describe people with dementia attending FDC and the impact FDC may have on the target group, several instruments will be used measuring quality of life, cognitive function, neuropsychiatric symptoms, depressive symptoms, anxiety symptoms, physical function, general health, social support, coping skills and use of health care resources (Table 1). In addition, general and sociodemographic data will be collected.

To describe the next of kin of people with dementia attending FDC and the impact FDC have on them, several instruments will be used measuring quality of life, care burden, initiating transfer of care, depressive and anxiety symptoms, physical function, social support, coping skills and use of health care resources. In

Table I Instruments used in the longitudinal study about people with dementia

\begin{tabular}{|c|c|c|}
\hline Construct & Instrument & Domains \\
\hline $\begin{array}{l}\text { General information } \\
(a, d)\end{array}$ & & $\begin{array}{l}\text { - Frequency of attending FDC } \\
\text { - Age, gender, marital status, level of education, living conditions } \\
\text { - Diagnosis, functioning (physically and mentally) } \\
\text { - Hobbies/interests, relationship to/experience with farming, activities at the farm } \\
\text { - Medications } \\
\text { - Diagnosis for research purpose }\end{array}$ \\
\hline Quality of life & $\begin{array}{l}\text { Quality of Life-Alzheimer's Disease } \\
\text { (QoL-AD) (a, d) } \\
\text { WHO-Five Well-being Index } \\
\text { (WHO-5) (a) }\end{array}$ & $\begin{array}{l}\text { A } 13 \text {-item questionnaire rated on a } 4 \text {-point scale with I being poor and } 4 \text { being } \\
\text { excellent. }{ }^{42} \\
\text { A } 5 \text {-item questionnaire on subjective well-being. }{ }^{43}\end{array}$ \\
\hline \multirow[t]{3}{*}{ Cognitive function } & $\begin{array}{l}\text { Montreal Cognitive Assessment } \\
\text { (MoCA), Version 7.I (a) }\end{array}$ & A one-page 30 -point test measuring the degree of cognitive impairment. ${ }^{44}$ \\
\hline & Clinical dementia rating (CDR) $(c, d)$ & $\begin{array}{l}\text { Structured-interview protocol assessing cognitive and functional performance in } \\
\text { six areas: memory, orientation, judgment and problem solving, community affairs, } \\
\text { home and hobbies, and personal care. A scale used to quantify the severity of } \\
\text { symptoms of dementia. } 45,46\end{array}$ \\
\hline & $\begin{array}{l}\text { The Anosognosia Rating Scale } \\
\text { (REED) (c, d) }\end{array}$ & One-item questionnaire assessing the level of insight in the memory deficiency. ${ }^{47}$ \\
\hline Psychological function & $\begin{array}{l}\text { The Neuropsychiatric Inventory } \\
\text { scale (NPI), } 12 \text { items }(b, d)\end{array}$ & $\begin{array}{l}\text { Scoring neuropsychiatric symptoms by the caregiver based on a standardized } \\
\text { interview administered by the researcher. Assessing } 10 \text { behavioral domains } \\
\text { common in dementia. Each domain is scored for frequency, severity and associated } \\
\text { caregiver distress. }{ }^{48}\end{array}$ \\
\hline \multirow[t]{2}{*}{ Depression } & $\begin{array}{l}\text { Montgomery Aasberg Depression } \\
\text { Rating Scale (MADRS) (a, d) }\end{array}$ & A 10 -item interview-based questionnaire rated on a scale from 0 to $6 .^{49}$ \\
\hline & Cornell $(b, d)$ & A 19-item interviewer-administered instrument rated on scale from 0 to $2 .{ }^{50}$ \\
\hline Anxiety & $\begin{array}{l}\text { Rating of anxiety in dementia } \\
\text { (RAID-N) }(a, b, c)\end{array}$ & A 18-item questionnaire rated on a scale from 0 to $3 .^{51}$ \\
\hline Physical function & $\begin{array}{l}\text { The General Medical } \\
\text { Health Rating (GMHR) (a, d) } \\
\text { Time up and go (TUG) (a) }\end{array}$ & $\begin{array}{l}\text { A rapid global rating scale of medical comorbidity in dementia patients rated on a } \\
\text { scale from } 1-4 .^{52} \\
\text { A functional test of physical mobility. }{ }^{53}\end{array}$ \\
\hline Activities of daily life & $\begin{array}{l}\text { Personal activities of daily life } \\
\text { (PADL) }(b, d) \\
\text { Instrumental activities of daily life } \\
\text { (IADL) }(b, d)\end{array}$ & $\begin{array}{l}\text { A } 6 \text {-item questionnaire rated on a scale from I to } 5\left(\text { Lawton }^{54}\right) \text {. } \\
\text { A 8-item questionnaire rated on a scale from } 0 \text { to } 3 / 4 / 5 .^{54}\end{array}$ \\
\hline General health & EQ-5D: VAS-scale $(a, d)$ & $\begin{array}{l}\text { A visual analog scale (VAS) describing subjective experience of health on a scale } \\
\text { from } 0 \text { to } 100.55\end{array}$ \\
\hline Social support & Oslo social support (OSS-3) (a) & Three items related to perceived social support. ${ }^{56}$ \\
\hline Coping skills & Locus of Control (LoC) $(a, d)$ & Seventeen statements rated on a scale from 0 (strongly disagree) to 6 (strongly agree). ${ }^{57}$ \\
\hline Health care resources & $\begin{array}{l}\text { Resource Utilization in Dementia } \\
\text { (RUD) }(a, d)\end{array}$ & Use of health care resources ${ }^{58}$ \\
\hline
\end{tabular}

Notes: (a) Answered by persons with dementia, (b) Answered by next of kin about persons with dementia, (c) Answered by researcher, (d) Used in the ECOD study. Abbreviation: FDC, Farm-based day care services. 
Table 2 Instruments used in the longitudinal study for next of kin

\begin{tabular}{|c|c|c|}
\hline Construct & Instrument & Domains \\
\hline General information & & $\begin{array}{l}\text { - Age } \\
\text { - Gender } \\
\text { - Occupational status } \\
\text { - Kinship with the person with dementia } \\
\text { - Use of other support services }\end{array}$ \\
\hline Quality of life & $\begin{array}{l}\text { Rand - } 36 \text { measure of health-related } \\
\text { quality of life } \\
\text { Quality of Life-Alzheimer's Disease } \\
\text { (QoL-AD) }\end{array}$ & $\begin{array}{l}\text { A } 36 \text {-item questionnaire. }{ }^{59} \\
\text { A I3-item questionnaire rated on a 4-point scale with I being poor and } 4 \\
\text { being excellent. }{ }^{42}\end{array}$ \\
\hline Burden of care & $\begin{array}{l}\text { Relatives sStress Scale (RSS) } \\
\text { Initiating transition of care (ITC) }\end{array}$ & $\begin{array}{l}\text { A } 15 \text {-item questionnaire indicating risk of clinically significant psychological } \\
\text { distress. }{ }^{60} \\
\text { One question measurement: "If the situation stays as it is now, how long } \\
\text { will you be able to cope with the care?" } 61\end{array}$ \\
\hline Depressive symptoms & $\begin{array}{l}\text { Montgomery Aasberg Depression Rating } \\
\text { Scale (MADRS) }\end{array}$ & A 10 -item interview-based questionnaire on a scale from 0 to $6{ }^{49}$ \\
\hline Anxiety symptoms & $\begin{array}{l}\text { The anxiety part of Hospital Anxiety \& } \\
\text { Depression Scale (HAD-A) }\end{array}$ & A 7-item questionnaire rated on a scale from 0 to $3 .^{62}$ \\
\hline Social support & Oslo social support (OSS-3) & Three items related to social support. ${ }^{56}$ \\
\hline Coping skills & Locus of Control (LoC) & $\begin{array}{l}\text { Seventeen statements rated on a scale from } 0 \text { (strongly disagree) to } 6 \\
\text { (strongly agree). }{ }^{57}\end{array}$ \\
\hline Health care resources & Resource Utilization in Dementia (RUD) & Use of health care resources. ${ }^{58}$ \\
\hline
\end{tabular}

addition, general and sociodemographic data will be collected (Table 2).

The instruments in Tables 1 and 2 will be filled in by the person with dementia during an interview, and the next of kin alone or during an interview. The interviewee will be a member of the research team.

\section{In-depth interviews with people with dementia and next of kin}

All individual in-depth interviews will be guided by an interview guide. It is preferable to conduct the interviews when the person with dementia is at the FDC, either during an activity if convenient or sitting down at the farm. If preferred by the person with dementia the interview will be conducted in the participant's home. Before conducting the interview with a person with dementia, the researcher will spend time on the farm to observe and participate in activities with the person.

Written notes from the observation will serve as background information and supplementary data for the interviews. Fangen ${ }^{63}$ emphasized that information from observation can make the interviewer more observant for details during the interview. Observation can also provide knowledge that can be amplified in the interview.
In-depth interviews with next of kin will be conducted in the participant's home or another preferable place.

\section{Data collection}

The study period will last from January 2016 to June 2020, and with data collection until February 2019.

The inclusion of participants for the quantitative longitudinal study is stipulated to last for 12 months. Three principal interviewers will collect data with assistant researchers. We will work in pairs as this could ease the burden for both the participants and the researchers; one researcher assessing the person with dementia and the other assessing the next of kin. We will also have an initial one-day training course for everybody collecting data in order to develop shared knowledge in doing the interviews. The interviewers will use a structured guide and get supervision from senior members of the team during the data collection period if needed.

Interviews with people with dementia and next of kin exploring the experience of FDC will be conducted from June 2017 to February 2019. Interviews with next of kin addressing the process when people with dementia are transferred to other care services will be conducted along the whole study period. 


\section{Analysis}

Descriptive data will be reported for the quantitative variables of interest. Appropriate statistical methods will be used to analyze data (eg Independent Samples $t$-test, chisquare, multiple regression, RM-Anova, regression models). ${ }^{64}$ Longitudinal data on people with dementia will be compared to anonymous data from the ECOD study. ${ }^{19}$

The qualitative interviews will be tape-recorded, transcribed and analyzed using qualitative content analysis methods in line with Graneheim and Lundman. ${ }^{65}$

\section{Discussion}

A multi-method approach is needed to explore the complex phenomenon of FDC for people with dementia in Norway. The protocol presented includes several sub-studies, with each aiming to shed light on different aspects of the field reflected in the research questions. We use quantitative designs to uncover measurable outcomes on different aspects of physical, mental and cognitive health and well-being over time, as well as qualitative methods for exploring the experience, and we reveal important elements of the service unfolding at the farm.

The longitudinal study will apply a single group design with the purpose of discussing and possibly comparing with comparable groups (ECOD protocol) ${ }^{19}$ To study health effects a randomized controlled trial would have been ideal, but for practical and ethical reasons, it is not feasible or appropriate to apply an experimental and randomized study design. People with dementia are in a vulnerable position and should not be exposed to the insecurity of randomizing a service that comprises a substantial part of their daily life. There is also a need to study the influence of the FDC through an observational design as this gives the best description of what the existing services may provide.

In the present study, we recruit users from all the estimated 34 FDC in Norway. ${ }^{13}$ From this survey, we estimate that the number of people attending FDC to be approximately 250 . The longitudinal study intends to recruit as many participants as possible, and we stipulate the number of possible dyads of users and next of kin for our study to be 150 . However, there may be several reasons why we will not be able to recruit this number of people with dementia attending FDC and their next of kin. First, not all will have a close next of kin seeing them every week, which is in line with our inclusion criteria.
Second, some will not have the capacity to participate due to cognitive status. The service providers or health care personnel in the municipalities will recruit the participants. Even though they are given the same oral and written information, their judgment on who may not have the capacity to participate may vary. Third, living with dementia or being next of kin to a person with dementia are often considered a burden, which could be a reason for declining participation in a research study. In addition, most people with dementia and their next of kin will be older and might be frail or have other health concerns. Fourth, some could decline participation because they do not fully understand the information given due to their cognitive symptoms, and they may be skeptical.

These reasons could cause selection biases threatening the internal validity of the study. ${ }^{66}$ For instance, the most vulnerable users of FDC could be excluded from the study. It would have been beneficial to register the characteristics of the participants not recruited. However, for privacy protection we are not recommended by the Norwegian Centre for Research Data (NSD) to note any demographical information on those not included. The FDCs are small and the participants could be identifiable by such information. We only have the permission to describe reasons for why users are not included and will therefore only be able to briefly describe those who do not want to participate.

One of the major challenges to conducting a longitudinal study on people with dementia is the progressive development of symptoms and we will probably face a certain number of drop-outs. The ECOD-study report that $75 \%$ dropped out after 24 month, ${ }^{41}$ and the authors of the study indicate to us that approximately $45 \%$ drop-out after 12 months. The present study will also follow the participants for 12 months, and we expect that several will not complete the longitudinal survey. However, we make use of the assumed dropout of participants to study why the users leave the day care service and we will conduct qualitative interviews with their next of kin.

Standardized, validated and well-known instruments to the field of dementia research are selected for our study. The instruments are in line with ones used in ECOD. ${ }^{19}$ It is important to secure information through valid and comparable outcome measures and thereby protect construct validity. ${ }^{66}$ The instruments require a certain level of functioning regarding language and understanding. People with dementia, especially in moderate and severe stage of the disease, often have reduced ability to understand and answer due to their cognitive status. However, we will 
add proxy measures from next of kin. Experiences from ECOD $^{19}$ indicate that this provides an important supplement to assessing people with dementia. Some of the instruments also require the ability to follow instructions (e g TUG, Table 1). This can lead to missing values and challenge statistical validity. ${ }^{66}$ Language problems and cognitive capacity might also challenge the qualitative interviews.

The scope of the study requires several researchers collecting data, in particular for the quantitative sub-studies. This might challenge the internal validity. ${ }^{66}$ To meet this challenge, we have arranged joint sessions to provide clear instructions on data collection. We discussed the setting, the instruments and potential challenges to strengthen validity before the data collection started. The study is also planned with common and frequent briefings/ debriefings to discuss matters that may arise during data collection.

To ease the burden for the participants, data collection for the qualitative interviews and the longitudinal study will all be conducted in a location that suits the participants, most likely their own home or at the farm. On the other hand, this could challenge the standardization of the conditions for data collection. Non-maleficence is an important ethical principal in research, ${ }^{67}$ and when interviewing people with dementia, we have an obligation to ensure security and comfort. There is also an obligation to be sensitive for how the participants cope with the assessment situation. Filling in cognitive measurements and understand that one is not doing so well, could be very challenging for the person with dementia.

Two of the principal interviewers for the quantitative measures will also conduct in-depth interviews to provide an extended understanding of the experience of people with dementia and next of kin. Reflexibility is an essential aspect of trustworthiness in qualitative studies. The researcher's background and position might affect the study, and openness and reflection in relation to all steps of the research process are required. ${ }^{68}$ In addition, before the interviews with participants are conducted, the two interviewers will be interviewed themselves to make their pre-understanding explicit.

\section{Concluding remarks}

The main aim of this study protocol is to gain knowledge regarding people with dementia attending FDC in Norway and their next of kin and how attending FDC may influence their health. Conducting research within the field of dementia leads to several challenges, such as the ability to include participants and keep them in the study for the whole study period, level of functioning regarding language and understanding and the vulnerability and burden many people with dementia and their next of kin experience in their daily life. Researchers therefore need to take special considerations. Despite these challenges, we believe that this study with its different angles will add important knowledge to the field. The multi-method approach, with qualitative and quantitative sub-studies, is important for exploring the complex phenomenon of FDC for people with dementia in Norway.

\section{Abbreviation}

FDC, Farm-based day care services.

\section{Ethics approval and informed consent}

The study has been approved by The Norwegian Centre for Research Data (No. 49,799). The first contact with the users of the FDC will be conducted by health care personnel or the service provider. The study has developed a procedure for evaluating capacity to give informed written consent, and the health care personnel or service provider will perform the evaluation. The users who have the capacity to consent, will be informed about the project and asked to provide written consent. Users without capacity to consent will also be informed, but the next of kin must give written consent on behalf of the person. Next of kin of the person with dementia attending FDC, will receive information and be asked to give a written consent to participate as next of kin. After the initial contact, the study researchers will follow up with the participants. The study will be conducted in accordance with the Declaration of Helsinki.

\section{Acknowledgment}

The present study is supported by the Research Council of Norway, grant number 255033.

\section{Author contributions}

All authors have contributed to the development of the study protocol, the first and last authors have drafted the article, and all the authors have contributed in revising it, approved the final version and agreed to be accountable for all aspects related to the accuracy or integrity. 


\section{Disclosure}

Professor Siren Eriksen reports grants from the Research Council of Norway, grant number 255033, outside the submitted work. Dr Ingeborg Pedersen reports grants from the Research Council of Norway, during the conduct of the study. Dr Lina Harvold Ellingsen-Dalskau reports grants from the Research Council of Norway, during the conduct of the study. Mr Bjørnar Finnanger Garshol reports grants from the Research Council of Norway, during the conduct of the study. Dr Grete Grindal Patil reports grants from the Research Council of Norway, during the conduct of the study. The authors report no other conflicts of interest in this work.

\section{References}

1. World Health Organization. Dementia. Fact sheet; 2017. Available from: www.who.int/news-room/fact-sheets/detail/dementia. Accessed March 20, 2019.

2. World Health Organization, Altzheimer's Disease International. Dementia: A Public Health Priority. World Health Organization. Geneva; 2012. Available from: http://www.who.int/mental_health/ publications/dementia_report_2012/en/. Accessed March 20, 2019.

3. Engedal K, Haugen P. Demens - Sykdommer, Diagnostikk Og Behandling [dementia - Diseases, Diagnostics and Treatment]. Tønsberg: Norwegian National Advisory Unite on Ageing and Health; 2017.

4. Prince M, Bryce R, Albanese E, Wimo A, Ribeiro W, Ferri CP. The global prevalence of dementia: a systematic review and metaanalysis. Alzheimers Dement. 2013;9(1):63-75 e62. doi:10.1016/j.jalz.2012. 11.007

5. Sanders S. Is the glass half empty or half full? Reflections on strain and gain in caregivers of individuals with Alzheimer's disease. Soc Work Health Care. 2005;40(3):57-73. doi:10.1300/J010v40n03_04

6. George LK, Gwyther LP. Caregiver weil-being: a multidimensional examination of family caregivers of demented adults. Gerontologist. 1986;26(3):253-259. doi:10.1093/geront/26.3.253

7. Bruvik FK Persons with dementia and their family carers - quality of life, burden of care, depression and the effect of psychosocial support [dissertation]. Oslo: University of Oslo; 2014.

8. Pinquart M, Sorensen S. Differences between caregivers and noncaregivers in psychological health and physical health: a meta-analysis. Psychol Aging. 2003;18(2):250-267.

9. Nortug B Caring burden of cohabitants living with partners suffering from chronic obstructive pulmonary disease or dementia [dissertation]. Trondheim, Norwegian University of Science and Technology; 2011.

10. Norwegian Ministry of Health and Care Services. Dementia Plan 2020 - a More Dementia Friendly Society. Oslo; 2015. Available from: https://www.regjeringen.no/en/dokumenter/dementia-plan2020/id2465117/. Accessed March 20, 2019.

11. Norwegian Ministry of Health and Care Services. Mestring, muligheter og mening [Mastery, possibilities and meaning]. White paper No: 25 (2005-2006). Oslo. 2006. Available from: https://www.regjerin gen.no/no/dokumenter/stmeld-nr-25-2005-2006-/id200879/sec1. Assessed March 20, 2019.

12. Gjøra L, Eek A, Kirkevold Ø. Nasjonal Kartlegging Av Tilbudet Til Personer Med Demens [national Survey of Services for People with Dementia]. Tønsberg: Norwegian National Advisory Unit for Ageing and Health; 2015.
13. Ibsen TL, Eriksen S, Patil GG. Farm based day care in Norway-a complementary service for people with dementia. JMDH. 2018;11:349. doi:10.2147/JMDH.S167135

14. Norwegian Ministry of Local Government and Regional Development and Ministry of Agriculture and Food. Inn På Tunet. Handlingsplan 2013-2017. [care Farming - Action Plan 20132017]. Oslo; 2013. Available from: https://www.regjeringen.no/no/ dokumenter/inn-pa-tunet/id735080/. Accessed March 20, 2019.

15. Norwegian Ministry of Food and Agriculture. Garden som ressurs marknaden som mål - vekst og gründerskap innan landbruksbaserte næringar [The farm as a resource - The market as a goal - Growth and entrepreneurship in agriculture based industry], White paper No: 31 (2014-2015). Assessed March 20, 2019.

16. Vernooij-Dassen M, Vasse E, Zuidema S, Cohen-Mansfield J, Moyle W. Psychosocial interventions for dementia patients in long-term care. Int Psychogeriatr. 2010;22(7):1121-1128. doi:10.1017/S104 1610210001365

17. Alm AK, Danielsson S, Porskrog-Kristiansen L, Non-pharmalogical interventions towards behavioural and psychological symptoms of dementia - an integrated literature review. Open $J$ Nurs. 2018;8:434-447. doi:10.4236/ojn.2018.87034

18. Caspar S, Davis ED, Douziech A, Scott DR. Non-pharmacological management of behavioral and psychological symptoms of dementia: what works, in what circumstances, and why? Innov Aging. 2018;1 (3):1-10.

19. Rokstad AMM, Engedal K, Kirkevold O, Benth JS, Barca ML, Selbaek G. The association between attending specialized day care centers and the quality of life of people with dementia. Int Psychogeriatr. 2017;29(4):627-636. doi:10.1017/S10416102160020 15

20. Reinar LM, Fure B, Kirkehei I, Dahm KT, Landmark B Effekten av tilrettelagt dagsentertilbud til personer med demens [The effect of adapted day care services for people with dementia]. Report No 21 2011. Oslo: National knowledge centre for health services; 2011.

21. Strandenæs MG, Lund A, Rokstad AMM. Experiences of attending day care services designed for people with dementia-a qualitative study with individual interviews. Aging Ment Health. 2018;22 (6):764-772. doi:10.1080/13607863.2017.1304892

22. Rokstad AMM, McCabe L, Robertson JM, Strandenaes MG, Tretteteig S, Vatne S. Day Care for People with Dementia: A Qualitative Study Comparing Experiences from Norway and Scotland. . Dementia (London); 2017.

23. Vandepitte S, Van Den Noortgate N, Putman K, Verhaeghe S, Verdonck C, Annemans L. Effectiveness of respite care in supporting informal caregivers of persons with dementia: a systematic review. Int J Geriatr Psychiatry. 2016;31(12):1277-1288. doi:10.1002/gps. 4504

24. Tretteteig S, Vatne S, Rokstad AM. The influence of day care centres for people with dementia on family caregivers: an integrative review of the literature. Aging Ment Health. 2016;20(5):450-462. doi:10.1080/13607863.2015.1023765

25. Pedersen I, Patil G, Berget B, Ihlebaek C, Gonzalez MT. Mental health rehabilitation in a care farm context: a descriptive review of Norwegian intervention studies. Work J Prev Assess Rehab. 2016;53 (1):31-43.

26. Pedersen I, Ihlebaek C, Kirkevold M. Important elements in farm animal-assisted interventions for persons with clinical depression: a qualitative interview study. Disabil Rehabil. 2012;34(18):1526-1534. doi:10.3109/09638288.2011.650309

27. Elings M, Hassink $J$ The added value of care farms and effects on clients. Paper presented at: Building Sustainable Rural Futures; 9th European IFSA Symposium; 2010; Vienna.

28. Hassink J, Elings M, Zweekhorst M, van Den Nieuwenhuizen N, Smit A. Care farms in the Netherlands: attractive empowermentoriented and strengths-based practices in the community. Health Place. 2010;16(3):423-430. doi:10.1016/j.healthplace.2009.10.016 
29. Hine R, Peacock J, Pretty JN. Care Farming in the UK: Evidence and Opportunities. Essex: University of Essex Report for the National Care Farming Initiative (UK); 2008.

30. Orr N, Wagstaffe A, Briscoe S, Garside R. How do older people describe their sensory experiences of the natural world? A systematic review of the qualitative evidence. BMC Geriatr. 2016;16(1):116. doi:10.1186/s12877-016-0288-0

31. Hendriks IH, van Vliet D, Gerritsen DL, Droes RM. Nature and dementia: development of a person-centered approach. Int Psychogeriatr. 2016;28(9):1455-1470. doi:10.1017/S1041610216000612

32. Swane CE. Green Care - the significance of nature to dementia sufferers. Sygeplejersken. 2005;14:22-26.

33. Gonzalez MT, Kirkevold M. Benefits of sensory garden and horticultural activities in dementia care: a modified scoping review. J Clin Nurs. 2014;23(19-20):2698-2715. doi:10.1111/jocn.12388

34. de Bruin S, Oosting S, Van Der Zijpp A, Enders-Slegers M-J, Schols J. The concept of green care farms for older people with dementia: an integrative framework. Dementia. 2010;9(1):79-128. doi:10.1177/ 1471301209354023

35. de Boer B, Hamers JP, Zwakhalen SM, Tan FE, Beerens HC, Verbeek H. Green care farms as innovative nursing homes, promoting activities and social interaction for people with dementia. $J$ Am Med Dir Assoc. 2017;18(1):40-46. doi:10.1016/j.jamda.2016.10.013

36. de Bruin SRD, Oosting SJ, Kuin Y, et al. Green care farms promote activity among elderly people with dementia. $J$ Housing Elder. 2009;23(4):368-389. doi:10.1080/02763890903327275

37. de Bruin S, Oosting S, Tobi H, Blauw Y, Schols J, De Groot C. Day care at green care farms: a novel way to stimulate dietary intake of community-dwelling older people with dementia? J Nutr Health Aging. 2010;14(5):352-357.

38. Taranrød LB. Mellom Hjem Og Institusjon: Dagtilbud Tilrettelagt for Personer Med Demens: Utviklingsprogram Om Dagtilbud Og Avlastningsordninger for Personer Med Demens [between Home and Institution: Day Care Services Adapted for People with Dementia: An Program on Day Care Services and Releif Support for People with Dementia]. Tønsberg: Norwegian National Advisory Unit for Aging and Health; 2012.

39. Strandli EHA, Skovdahl K, Kirkevold Ø, Ormstad H. Inn på tunet- et helsefremmende tilbud-En studie om ektefellers opplevelse med dagaktivitetstilbud for personer med demens [care farming - a health promotion intervention. A study on spouses' experiences with day care services for people with dementia]. Tidsskr Omsorgsforsk. 2016;2(03):202-211. doi:10.18261/issn.2387-5984-2016-03-06

40. Foss C, Ellefsen B. The value of combining qualitative and quantitative approaches in nursing research by means of method triangulation. $J$ Adv Nurs. 2002;40(2):242-248.

41. Rokstad AMM, Engedal K, Kirkevold Ø, Benth JŠ, Selbæk G. The impact of attending day care designed for home-dwelling people with dementia on nursing home admission: a 24-month controlled study. BMC Health Serv Res. 2018;18(1):864. doi:10.1186/s12913-0183686-5

42. Logsdon RG, Gibbons LE, McCurry SM, Teri L. Quality of life in Alzheimer's disease: patient and caregiver reports. J Ment Health Aging. 1999;5:21-32.

43. World Health Organization, Well-being Measures in Primary Health Care-the DepCare Project . Copenhagen 1998. Available from: http:// www.euro.who.int/_data/assets/pdf_file/0016/130750/E60246.pdf. Assessed March 20, 2019.

44. Nasreddine ZS, Phillips NA, Bedirian V, et al. The montreal cognitive assessment, MoCA: a brief screening tool for mild cognitive impairment. J Am Geriatr Soc. 2005;53(4):695-699. doi:10.1111/ j.1532-5415.2005.53221.x

45. Hughes CP, Berg L, Danziger WL, Coben LA, Martin RL. A new clinical scale for the staging of dementia. Br J Psychiatry. 1982;140 (6):566-572. doi:10.1192/bjp.140.6.566
46. Morris JC. The Clinical Dementia Rating (CDR): current version and scoring rules. Neurol. 1993;43(11):2412-2414. doi:10.1212/WNL.43. $11.2412-\mathrm{a}$

47. Reed BR, Jagust WJ, Coulter L. Anosognosia in Alzheimer's disease: relationships to depression, cognitive function, and cerebral perfusion. J Clin Exp Neuropsychol. 1993;15(2):231-244. doi:10.1080/ 01688639308402560

48. Cummings JL, Mega M, Gray K, Rosenberg-Thompson S, Carusi DA, Gornbein J. The neuropsychiatric inventory comprehensive assessment of psychopathology in dementia. Neurol. 1994;44 (12):2308. doi:10.1212/WNL.44.12.2308

49. Montgomery SA, Asberg M. A new depression scale designed to be sensitive to change. $B r \quad J$ Psychiatry. 1979;134(4):382-389. doi:10.1192/bjp.134.4.382

50. Alexopoulos GS, Abrams RC, Young RC, Shamoian CA. Cornell scale for depression in dementia. Biol Psychiatry. 1988;23(3):271284.

51. Shankar KK, Walker M, Frost D, Orrell MW. The development of a valid and reliable scale for rating anxiety in dementia (RAID). Aging Ment Health. 1999;3(1):39-49. doi:10.1080/13607869956424

52. Lyketsos CG, Galik E, Steele C, et al. The general medical health rating: a bedside global rating of medical comorbidity in patients with dementia. J Am Geriatr Soc. 1999;47(4):487-491. doi:10.1111/ j.1532-5415.1999.tb07245.x

53. Podsiadlo D, Richardson S. The timed "up \& go": a test of basic functional mobility for frail elderly persons. J Am Geriatr Soc. 1991;39(2):142-148. doi:10.1111/j.1532-5415.1991.tb01616.x

54. Lawton MP, Brody EM. Assessment of older people: self-maintaining and instrumental activities of daily living. Nurs Res. 1970;19(3):278. doi:10.1097/00006199-197005000-00029

55. Kunz S. Psychometric properties of the EQ-5D in a study of people with mild to moderate dementia. Qual Life Res. 2010;19(3):425-434. doi:10.1007/s11136-010-9600-1

56. Dalgard OS, Dowrick C, Lehtinen V, et al. Negative life events, social support and gender difference in depression: a multinational community survey with data from the ODIN study. Soc Psychiatry Psychiatr Epidemiol. 2006;41(6):444-451. doi:10.1007/s00127-006-0051-5

57. Craig AR, Franklin JA, Andrews G. A scale to measure locus of control of behaviour. Psychol Psychother. 1984;57(2):173-180.

58. Wimo A, Jonsson L, Zbrozek A. The resource utilization in dementia (RUD) instrument is valid for assessing informal care time in community-living patients with dementia. $J$ Nutr Health Aging. 2010;14 (8):685-690.

59. Jr JE W, Sherbourne CD, The MOS. 36-item short-form health survey (SF-36): I. Conceptual framework and item selection. Med Care. 1992;30(6)473-483.

60. Greene JG, Smith R, Gardiner M, Timbury GC. Measuring behavioural disturbance of elderly demented patients in the community and its effects on relatives: a factor analytic study. Age Ageing. 1982;11(2):121-126. doi:10.1093/ageing/11.2.121

61. Kraijo H, Brouwer W, de Leeuw R, Schrijvers G, van Exel J. The perseverance time of informal carers of dementia patients: validation of a new measure to initiate transition of care at home to nursing home care. J Alzheimers Dis. 2014;40(3):631-642. doi:10.3233/JAD132420

62. Zigmond AS, Snaith RP. The hospital anxiety and depression scale. Acta Psychiatr Scand. 1983;67(6):361-370.

63. Fangen K. Deltagende Observasjon. Bergen: Fagbokforlaget; 2010.

64. Field A. Discovering Statistics Using IBM SPSS Statistics. Fifth ed. Los Angeles: SAGE Publishing; 2018.

65. Graneheim UH, Lundman B. Qualitative content analysis in nursing research: concepts, procedures and measures to achieve trustworthiness. Nurse Educ Today. 2004;24(2):105-112. doi:10.1016/j.nedt. 2003.10.001 
66. Shadish WR, Cook TD, Campbell DT. Experimental and Quasiexperimental Designs for Generalized Causal Inference. 2nd ed. Hampshire: Cengage Learning; 2002.

67. Schuklenk U. Protecting the vulnerable: testing times for clinical research ethics. Soc Sci Med. 2000;51(6):969-977.
68. Malterud K. Qualitative research: standards, challenges, and guidelines. Lancet. 2001;358(9280):483-488. doi:10.1016/S0140-6736(01) 05627-6

\section{Publish your work in this journal}

The Journal of Multidisciplinary Healthcare is an international, peerreviewed open-access journal that aims to represent and publish research in healthcare areas delivered by practitioners of different disciplines. This includes studies and reviews conducted by multidisciplinary teams as well as research which evaluates the results or conduct of such teams or healthcare processes in general. The journal covers a very wide range of areas and welcomes submissions from practitioners at all levels, from all over the world. The manuscript management system is completely online and includes a very quick and fair peer-review system. Visit http://www.dovepress.com/testimonials. php to read real quotes from published authors. 